7. Gardener JH, Amonette RA, Chesney TM. Angiolymphoid hyperplasia with eosinophilia. J Dermatol Surg Oncol 1981;7:414.

8. Rao RN, Spurlock BO, Witherington R. Angiolymphoid hyperplasia with eosinophilia: report of a case with penile lesions. Cancer 1981;47:944.

9. Baler GR. Angiolymphoid hyperplasia with eosinophilia: a report of two cases. J Dermatol Surg Oncol 1981;7:229.

10. Daniels DG, Schrot R, Fliegelman MT, Owen LG.

Ultrastructural study of a case of angiolymphoid hyperplasia with eosinophilia. Arch Dermatol 1974;109:870.

11. Mehregan AH, Shapiro L. Angiolymphoid hyperplasia with eosinophilia. Arch Dermatol 1971;103:50.

12. Lyon DB, Tang TT, Kidder TM. Epithelioid

hemangioendothelioma of the orbital bones. Ophthalmology 1992;99:1773-8.

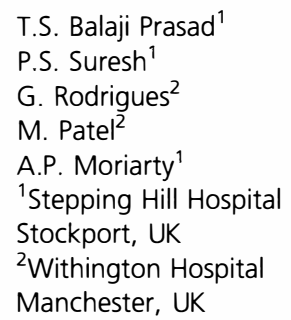

Sir,

\section{Bilateral multifocal choroidal metastases as the first manifestation of a breast carcinoma}

Breast cancer is the most common malignancy among women in Western societies. In the European Union, breast cancer represents $28 \%$ of all female cancers. Rates are highest in Northern and Western Europe, with the exception of France, which has a relatively low rate, in common with Greece, Spain and Portugal. ${ }^{1}$ The incidence rates of breast carcinoma in the United States, as well as in European countries, are increasing steadily, whereas mortality caused by the disease is fairly constant. The age-adjusted incidence of breast cancer among US women rose by over 30\% during the $1980 \mathrm{s.}^{2}$ Although breast cancer haematogenous metastases favour the skeleton, lung, pleura and liver, virtually any anatomical site may be involved.

We describe an unusual case of primary breast carcinoma that had not presented earlier. The patient initially presented with visual problems, due to bilateral multifocal choroidal metastases. The clinical presentation, the angiographic and ultrasonographic findings of the uveal lesions implied a metastatic process. Results from a mammogram established the diagnosis.

\section{Case report}

A 42-year-old woman presented with a 1 week history of metamorphopsia in the left eye. Neither her ocular nor her medical history were notable. The Snellen visual

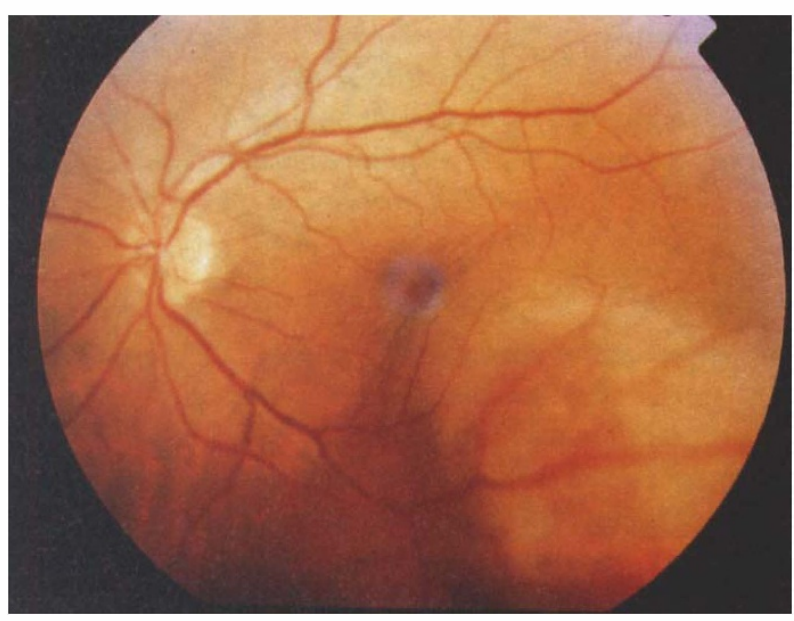

(a)

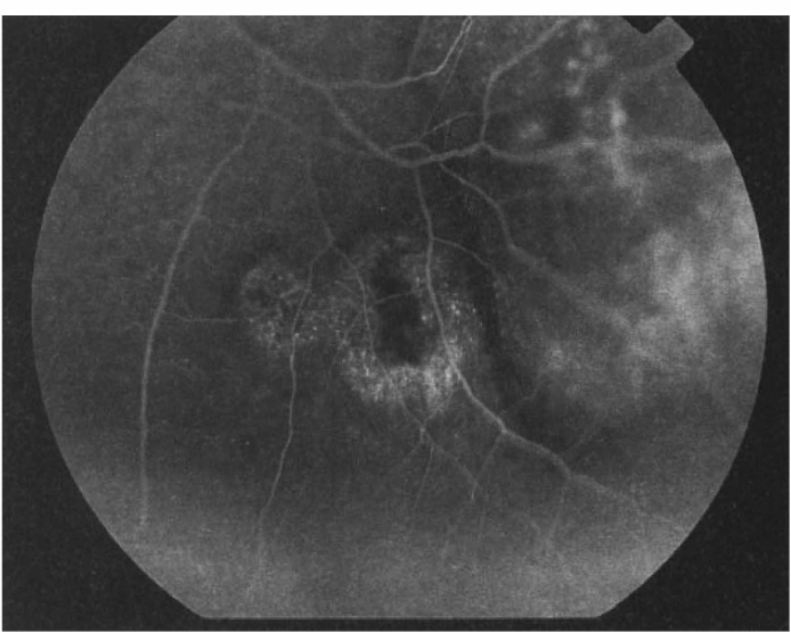

(b)

Fig. 1. Left eye. (a) Fundus examination shows a yellowish-orange, round, amelanotic, well-circumscribed mass, inferotemporal and adjacent to the macula, that extends below the inferior arcade. An

acuity was $20 / 20$ in each eye. The anterior ocular segments were normal. Fundus examination of the left eye showed a yellowish-orange, round, amelanotic, well-circumscribed mass inferotemporal and adjacent to the macula, that extended below the inferior arcade. An overlying serous retinal detachment extended into the macula causing metamorphopsia (Fig. 1a). Right fundus examination revealed a similar mass, inferonasally to the optic disc, about 1 disc diameter away from it.

Fluorescein angiography of the left eye revealed two additional choroidal lesions, nasal to the larger mass (Fig. 1b). On fluorescein angiography of the right eye there was a highly fluorescent mass located nasal to the optic disc (Fig. 2a) and three flat choroidal lesions, two in the inferotemporal area and one 3 disc diameters temporal to the macula (Fig. 2b). All lesions were rather well circumscribed, round or oval in shape. In the venous phase there was irregular progressive hyperfluorescence at the centre of the lesions and small hyperfluorescent dots at their margins. There was also retinal capillary dilation with late dye leakage. 


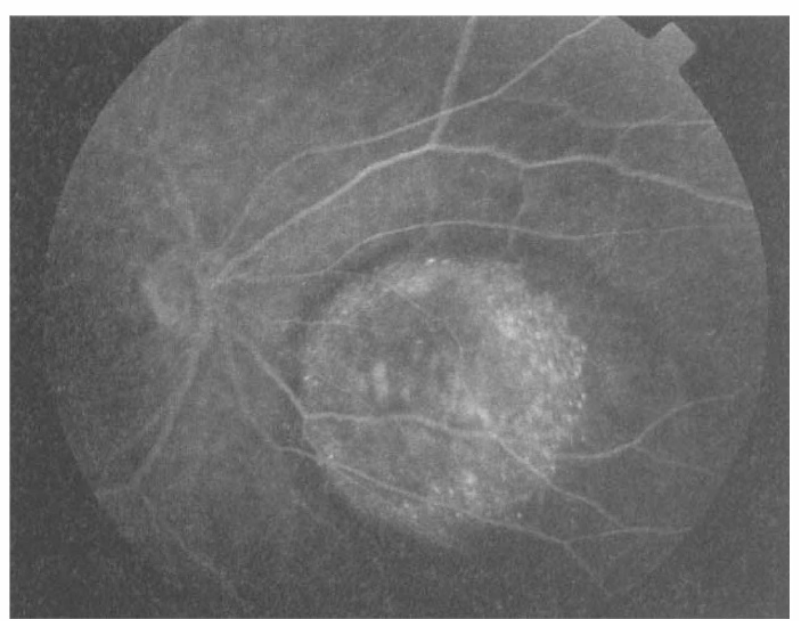

(a)

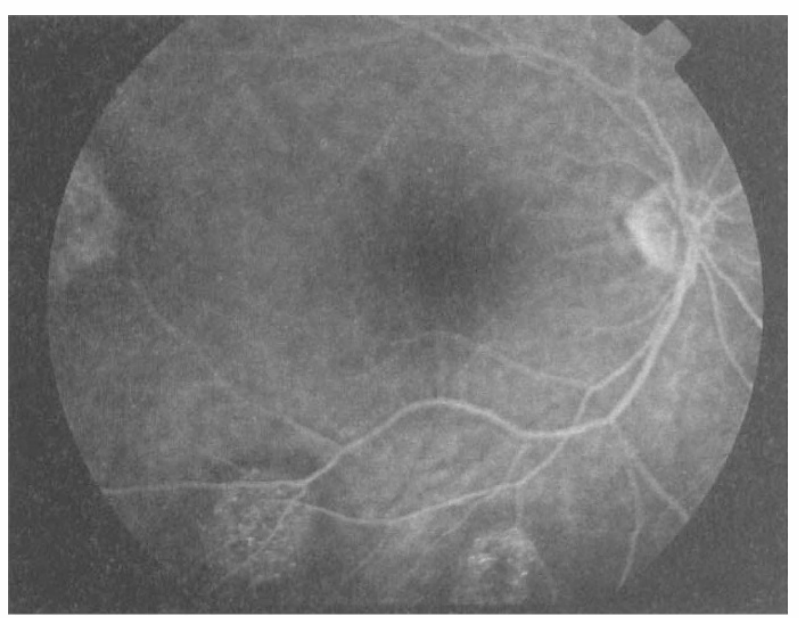

(b)

Fig. 2. Right eye. (a) An elevated lesion, nasal to the optic disc, can be observed. (b) There are also three additional flat choroidal lesions, two in the inferotemporal area and one 3 disc diameters temporal to the macula.

Standardised B-scan ultrasonography showed one solid tumour in each eye, with a maximum base diameter of $6.0 \mathrm{~mm}$ and a maximum elevation of $3.5 \mathrm{~mm}$. A chest radiograph did not reveal any abnormal findings, but the mammogram showed a breast carcinoma. MRI did not reveal any other site involved. The patient underwent a radical mastectomy with axillary node dissection combined with systemic chemotherapy.

\section{Comment}

The uveal tract is the most highly favoured target site for the development of metastases per unit of delivered cancer cells via the arterial route. ${ }^{3}$ Uveal metastases represent the most common malignant neoplasms of the adult eye. ${ }^{4}$ They most often result from breast carcinoma in women (47-55\% of the cases) and from lung cancer in men (13-21\% of the cases). ${ }^{5,6}$ Choroidal metastases from breast carcinoma have been found to be bilateral in $41-64 \%$ of patients and the choroid was the first site of metastasis in 25-30\%. ${ }^{6,7}$ Shields et al., ${ }^{6}$ in their major survey on 520 eyes with uveal metastases, reported that
$34 \%$ of the patients had no history of cancer. Of those patients, only $7 \%$ showed a primary tumour in the breast. Of the eyes with choroidal metastases only $0.54 \%$ had three foci and $0.44 \%$ had four foci. The principal symptom was blurred or distorted vision. Only a minority of patients with uveal metastases had 20/30 visual acuity or better. The results of a prospective screening programme in patients with disseminated breast cancer demonstrated that asymptomatic choroidal metastasis occurs in $5 \%$ of the patients and in only $0.08 \%$ of them are the metastases bilateral. ${ }^{8}$

Choroidal metastases have an unfavourable prognosis (median survival 11 months) and are related to heavy metastatic involvement even if the latter is not evident. $^{9}$

We believe the case we present here is an unual one, since the majority of patients with uveal metastases have a prior history of cancer. In our case, the breast cancer had not presented earlier and the bilateral, multifocal choroidal metastases constituted the first clinical manifestation of breast carcinoma.

\section{References}

1. Black RJ, Bray F, Ferlay J, Parkin DM. Cancer incidence and mortality in the European Union: cancer registry data and estimates of national incidence for 1990. Eur J Cancer 1997;33:1075-107.

2. Lantz PM, Booth KM. The social construction of the breast cancer epidemic. Soc Sci Med 1998;46:907-18.

3. Weiss L. Analysis of the incidence of intraocular metastasis. $\mathrm{Br}$ J Ophthalmol 1993;77:149-51.

4. Shields JA, Shields CL. Intraocular tumors: a text and atlas. Philadelphia: WB Saunders, 1992:208.

5. Bourgoignie K, de Laey JJ. Diagnosis of choroidal metastasis. Bull Soc Belge Ophtalmol 1993;248:37-45.

6. Shields C, Shields J, Gross N, Schwartz G, Lally S. Survey of 520 eyes with uveal metastases. Ophthalmology 1997;104:1265-76.

7. Thacher N, Thomas P. Choroidal metastases from breast carcinoma: a survey of 42 patients and the use of radiation therapy. Clin Radiol 1975;26:549-53.

8. Wiegel T, Kreusel KM, Bornfeld N, Bottke D, Stange M, Foerster $\mathrm{MH}$, et al. Frequency of asymptomatic choroidal metastasis in patients with breast cancer: results of a prospective screening programme. Br J Ophthalmol 1998;82:1159-61.

9. Halpern J, Sofinski SJ, Forgach PW, Khilchenko S, Ambus JL. Choroidal metastases arising from carcinoma of the breast: review and analysis of five cases. J Med 1986;17:1-11.

Ephigenia K. Mela

John X. Koliopoulos

Panagiotis K. Lagogiannis

Anna D. Giannopoulou

Konstantinos D. Georgakopoulos

Sotirios P. Gartaganis

Department of Ophthalmology

University of Patras Medical School

Patras, Greece

Ephigenia K. Mela, MD

Department of Ophthalmology

University of Patras Medical School

26500, Rion, Patras, Greece

Tel: +3061420672

e-mail: ifigenia@hol.gr 